\title{
Color As A Significant Atmospheric Factor Of Merchant Websites: A Moroccan Exploratory Study
}

\author{
Lahmidi Zineb and Aomari Amina
}

\begin{abstract}
Our exploratory study highlights the influence of environmental characteristics on individuals' behavior in the commercial context. More particularly, it evaluates the importance of "color" as an atmospheric component in the context of e-commerce websites and it mesures its impact on the Moroccan web user.

The literature review around the subject allowed us to brush the features of the commercial atmosphere both traditional and virtual, putting the component of "color" in the center of our interest.

The conducted qualitative study via semi-directive interviews has brought to light the variables of our research confronted to the results of the literature.
\end{abstract}

Index Terms - color; commercial atmosphere; e-commerce; influence; Moroccan web user.

\section{INTRODUCTION}

With the increasing progress of the World Wide Web, the effectiveness of commercial efforts applied to websites has been questioned [1]. Indeed, very few researches have been conducted on the atmosphere of websites [2].

Thenceforth, many studies such as Lemoine's [3] [4] have highlighted a certain convergence between the physical atmospheres associated to traditional points of sale and virtual atmospheres related to e-commerce websites.

Indeed, if in a traditional store, the consumer travels through spaces, departments, products, advertisements, all arranged in such a way so as to attract his attention and thus push him to purchase. At the same time, we find on a website, pages highlighting a whole mechanism of attraction, using stimuli around color, music, animations... etc.; all part of the virtual atmosphere of e-commerce websites.

Thus, by transposing the definition suggested by Kotler [5] related to the concept of the atmosphere, Dailey [6] sees it as: "the voluntary conception of the Internet environment which aims to create positive effects on the web users, in order to generate favorable answers as to: revisit it again, spend more time and possibly place an order."

It is through this vision that Dailey [6] proposes a definition of the virtual environmental index, which refers to "any web interface element contained in the perceptual field of the individual and likely to stimulate his senses, as suggested by Milliman \& Fugate [7]".

Published on December 24, 2019.

Zineb Lahmidi is a PhD student in the Faculty of Economic and Social Legal Sciences- Souissi, Mohammed V University of Rabat, Morocco. (e-mail: Zineb.lahmidi@um5s.net.ma)

Amina Aomari is a teacher- researcher in the Faculty of Economic and Social Legal Sciences- Souissi, Mohammed V University of Rabat, Morocco.
Thereby, color in the context of e-commerce websites is considered as a virtual environmental index, which has a crucial role in the appearance of the website interface; about $80 \%$ of the collected information comes from sight [8], and thus contributes to the creation of a favorable and conducive virtual climate that can influence the web user's behavior.

In this perspective, color as an atmospheric component of the e-commerce website interface is manipulated as an explanatory variable of the web user's behavior.

\section{LITERATURE REVIEW}

As it can be defined in several facets, color is intended to be present in all disciplinary fields. Whether in physics by studying the link between color and light, in chemistry by focusing on the reactions between the coloring material and the object, in the artistic field where the Greco-Roman world sees it as an instrument of fascination and a tool of persuasion [9] or in psychology by focusing rather on the impact of color on the subconscious of the individual [10], the definition of the notion "color" remains linked to the fields of analysis to which it refers.

On an e-commerce website, color is generally presented in the form of flat areas; the dominant color is the background color while the dynamic color is variable in terms of text including the colors of typographies, buttons, tables, images and animations [11].

According to Shih [12], the atmospheric characteristics by which consumers perceive the quality of products and services are now perceived as effectiveness criteria of an ecommerce website. Color is one of the key elements that has a significant impact on the perception of a commercial website

In order to clarify the scope of our theoretical framework, it is necessary to focus first on both the classical and virtual commercial atmosphere, by evoking the location of color as an atmospheric element of the commercial environment and then by emphasizing the characteristics of color from different angles of view.

\section{A. Commercial atmosphere: The classic and the virtual one}

Generally, the atmosphere is perceived as the characteristic of commerce that describes the perceived quality of the environment, whether bad, good or pleasant [13].

The first theoretical researches on the notion of atmosphere were those of Kotler [5], based on the foundations established by Mehrabian and Russell [14] in the field of environmental psychology.

Thus, in the context of traditional purchasing; related to 
classical commerce, many empirical studies have focused on the study of atmospheric variables, namely music [15] [16], brightness [17], color [18], odor [19] and their impacts on consumer responses.

It was therefore found that each of these specific atmospheric variables played a crucial role in creating a conducive and suitable environment for sale.

For Kotler [5], the notion of atmosphere also refers to the way in which the point of sale is carefully designed to produce emotional effects, which may increase the probability of purchase by transforming the behavioral intentions of the buyer into actual purchasing behaviors.

In 1987, Derbaix [20] describes the atmosphere as the spatial arrangement privileging the affective dimension of the individual: well-being, appreciation, joy

These two perceptions of the atmosphere allow us to consider the atmosphere as a term that refers to the point of sale in its general structure but also to the atmosphere created by the presence of several factors, particularly social factors, which certainly has an impact on consumer behavior.

Other contributions define the atmosphere by referring to three dimensions:

- The ambient environment (music, colors, light...);

- The architectural environment or design (store layout, product layout, etc.)

- The social environment (including social factors such as employee helpfulness and friendliness) [21], [22], [23], [24].

As for the virtual atmosphere, the one related to the ecommerce website, it can be defined as all the constituent elements of a website, impacting the visual and auditory fields of the web user likely to awaken and activate his senses.

The atmosphere of a website allows the understanding of the web user's emotional, physiological, cognitive and behavioral reactions regarding the slightest change made to one of its components [11].

In 2004, Dailey [6] sees in the Internet atmosphere "the design of the Internet environment that aims to create positive effects for the web user, on an emotional and cognitive level, in order to obtain favorable feedback as well as to resume navigation on the same site".

For Menon and Kahn [25], the consumer's intention to approach or avoid certain stimuli in a specific environment is now dependent on his emotional reaction as for the general atmosphere.

The consumer's emotional reaction will certainly influence his behavior around an environment as dynamic as the Internet.

Therefore, a pleasant experience will generate a positive approach behavior that the consumer could extend to explore more topics and products.

\section{B. Color: Atmospheric element of the commercial environment}

Long ago, atmospheric components have played a key role in allowing customers to evaluate the proposed product offering, even if only mentally [26].

Thus, the atmosphere of a point of sale is perceptible by all the senses of the individual. It is seen, heard, touched and even smelled [26].

Therein, many authors have proposed to present a classification of the environmental elements and atmospheric components of a commercial point of sale, by focusing on the effects produced by the commercial environment on the consumer.

Indeed, three main authors; namely Kotler [26], Baker [21] and Berman \& Evans [27] respectively explain the different atmospheric components within the commercial space [28]:

\section{- $\operatorname{Kotler}(1974)$}

Kotler [26] defines the atmosphere according to a sensory logic, dividing it into four characteristics:

- The visual characteristic: essentially comprising color, size and shape;

- The auditory characteristic: containing volume and tone, especially when it comes to music;

- The olfactory characteristic: this is the case for diffused odors, perfumes and scents;

- The tactile characteristic: it is the sensation received during tactile contact with the product, but also the temperature degree associated with it.

Thus, Kotler highlights the vital role of the visual chromatic characteristic "color", which is not only an aesthetic component but also an essential marketing tool strongly recommended in a context of high competition, marked by imitation and where it is difficult to differentiate between products [29].

\section{- Baker (1986)}

In 1986, Baker [21] classified the atmospheric components into three categories, combining them with design, background and social environment. This is the case with:

- The architecture, the decorative style, the layout of the furniture and the color of the walls; all integrating the design dimension;

- Temperature, noise and odors, forming the background of the general environment of the point of sale;

- The social factor translates into the behavior and appearance of both consumers and employees.

Indeed, color is one of the atmospheric components of design, which according to Baker, alike to the smell with the evocative power, influences the individual's subconscious mind to also impacts emotions and thus stimulate the individual [21].

\section{- Berman and Evans (1995)}

In 1995, Berman and Evans [27] also grouped the elements of the atmosphere into five dimensions:

- External factors such as the garden, the neighbourhood, the availability of parking...

- General interior factors such as colors, lighting, odors, music, temperature...

- Design factors concerning the layout of the space, the scheduling and installation of work equipment, the waiting room...

- The elements related to the point of sale and its decorative aspect, and this, around the instructions for use, the cards, decorative motifs on the walls in particular... 
- The human dimension containing the specificities of employees and consumers as well as their uniforms or work clothes...

Certainly, color appears among the general interior factors, which is similar to Baker's classification, noting that color first influences consumers' emotions and perceptions well before it affects the behavioral aspect.

Thus, we can clearly observe that color represents the most meaningful visual dimension within the commercial environment.

\section{The importance of color in the virtual commercial atmosphere}

Due to many researches on the consumer behavior, sight (since the eye is the sense that influences most people in general and the consumer in particular) as well as hearing are the web user's most stimulated senses.

Color is a significant component of the values conveyed by the e-commerce website.

Obviously, the e-commerce Websites atmosphere is based on the appearance of their interfaces. Thus," (...) about $80 \%$ of our information comes from the visual sense and (...) other forms of perception of the environment are themselves closely influenced by sight" [8].

The perception of the website atmosphere resides almost exclusively in its visual aspect since $80 \%$ of the information processed by the web user's brain comes from sight [29].

Among the behavioral reactions caused by the website atmosphere, there is the frequency of visiting the website, which depends on the colors considered as a positive influencing factor. However, an inappropriate use of colors in an e-commerce website can influence negatively the web user's behavior [4].

Thus, an adapted use of color as an atmospheric factor remains a vital lever of action, a tool that encourages the web user to be stimulated, retains visitors, encourages purchases and builds customer loyalty [28].

\section{EMPIRICAL STUDY}

Before presenting the results of our exploratory study, we will first present the research methodology used during its realization.

\section{A. Methodology}

As part of our qualitative exploratory research, we conducted semi-directive interviews to collect the needed informations for our exploration.

The constitution of the semi-directive interviews is based on different themes through open questions to allow respondents to express themselves freely.

To complete this study and determine the number of interviewees, we used the saturation approach; generally adopted in marketing research [32].

Once the saturation was reached, our purpose was to collect as much information as possible about the impact of "color", as an atmospheric component, on the web user.

Thus, our research resulted in a total of 10 interviews (before the aforementioned saturation was achieved).

The interviews were conducted with webmasters: designers and owners of e-commerce Websites.

Our analysis can be summarized in three main phases:
- The retranscription of data: which allows the organization of the survey material in an easily analyzed form [33]. It consists on formatting all the raw information collected.

- The coding of information: we proceeded by transforming the meaningful raw information into key ideas or lebel embodying a notion or a variable.

- Data processing: It involves interpreting the point of view of the interviewees based on the questions asked by the interviewer. It is a phase that lies in the diagnosis of the previously coded data by determining the strengths and weaknesses [34].

The analysis of the interviews was assisted by the textual analysis software "Nvivo" in its 10th and 11th versions. The flexibility offered by Nvivo has allowed us to organize and manage textual data in a better way.

\section{B. Results and discussion}

We chose to synthesize the findings of the exploratory qualitative study through the conceptually clustered matrix of Miles and Huberman [35], for a more detailed interpretation of the primary data.

We structured the interpretation of the results around four sub-themes that highlight the importance of the color component in the virtual interface of e-commerce websites.

\section{- A typical e-commerce website}

According to the interviewed webmasters, a typical ecommerce website has an interface that allows the visitor to understand, at first sight, the type of the proposed offer, and provides easy navigation but also accessible information.

Similarly, it is a platform that takes into consideration the ergonomics and structure of the various sections so that they are easily identified, perfectly manageable by the web user and therefore easy to understand.

According to websites designers, a typical e-commerce website is the one that attracts and captivates the visitors so that they can easily remember it, especially if they spend a lot of time there.

Thus, a typical e-commerce website must be aesthetically attractive mainly through color or combination of colors, in order to make the visitor want to buy and explore more the virtual commercial space with all its offers.

"A typical e-commerce website is the one that gives its visitors a simple and easy use, a quick navigation and a pleasant exploration of products..." (1st interviewee: designer and e-commerce website owner)

"... A typical e-commerce website must be imperatively accessible by the visitor. I mean by accessible: organized, well structured and where the visitor by consulting it and browsing does not get lost, he is easily oriented... It is also a website that makes you want to buy and discover more sections, products... It is where the visitor spends a lot of time by getting information about everything in it..." (2nd interviewee : graphic designer)

\section{- Important atmospheric factor}

According to the interviewed webmasters, the visual aspect (the appearance) of the website is the first factor to which the web user pays attention. It's actually a decisive factor for the visitor to continue browsing the e-commerce 
website or to leave it immediately.

This visual aspect mainly includes the design elements, namely: the architecture of the website in terms of navigation, colors, graphic charter and ergonomics... These elements must be in perfect synchronization with the entire e-commerce website as well as with the type of offer proposed in order to transmit the right image to the web user.

"The design and general structuring of the website can motivate or demotivate the e-visitor to return or not to return to the virtual platform and thus contribute to build a first impression of the e-commerce website..." (4th interviewee: designer)

We may say that the vast majority of e-consumers think that the visual aspect and general appearance of the ecommerce website (design, aesthetics and layout of the sections) are decisive for the purchase decision.

"... A study on the incidence of color showed that it is very likely that two quarters of customers will not buy the product if they don't find the color they want... For the econsumer, color is one of the first visual elements that triggers the purchase of certain products..." (9th interviewee : owner of communication agency).

Thus, there is a close relationship between the structure of the e-commerce website and the color combination of its graphic charter. Indeed, the designer is required to choose the appropriate color combination by taking into account the type of the e-commerce website, its target, the graphic charter's components and ergonomics, in order to ensure the best synchronization.

Similarly, the browsing quality factor is also important and highly noticed by the web user;

"A commercial site must be very easy to navigate and accessible to get the needed information ... It meets the criteria of simplicity, speed and ease of use ..." (1st interviewee: designer and e-commerce website owner)

In parallel to the appearance and navigability factors, the social factor illustrated through comments, discussion, forums and FAQs are among the most important atmospheric factors, since it ensures good interactivity between the e-commerce website interface and the

e-consumer. The social factor contributes to reinforce the web user's confidence in the website and its products.

"...For the web user, the social factor compared to the design and navigability factors represents the one that stimulates the e-commerce website memorization the most..., due to interactivity and exchange that it grants to active web users and thus the trust in the

e-commerce website is strengthened. " (9th interviewee: owner of a commercial agency)

\section{- The importance of color choice}

The choice of color is essential, since it influences the first vision of the web user regarding the e-commerce website.

Therefore, the color of an e-commerce website can't be chosen arbitrarily, it must be in perfect synchronization with the graphic charter so as to attract the web user without irritating his eyes.

"... Actually, it is a matter of identifying the colors from the client's visual identity. The visual identity includes generally the logo and the slogan in addition to the colors related to it. Therefore, it's preferable to use a maximum of two or three predominant colors with some variations. " (3rd interviewee : graphic designer)

Thus, from the first visual contact of the web user with the commercial platform, the role of color is highlighted.

Certainly, the color in an e-commerce website plays a purely aesthetic role since it is designed to give a pleasant and playful aspect to the commercial website in order to facilitate browsing.

Thus, color has a high unconscious psychological impact on the web user.

Because at the first sight of the website, the customer must be captivated by a given element and color is one of the most important elements that ensure the attachment and attraction of the web user.

"... It should also be noted that approximately $75 \%$ of the first impression or opinion attributed to any e-commerce website is based on color only... " (2nd interviewee : graphic designer)

Color also promotes the creation of the visual identity of the e-commerce website and thus facilitates its immediate recognition.

"... Colors contribute enormously to the creation of brand identity. Colors attract the attention of e-consumers, awaken emotions and raise the brand's visibility by allowing immediate recognition..." (5th interviewee : graphic designer)

\section{- Lived experience}

The web user's lived experience while browsing an ecommerce website is decisive for his subsequent behavior toward the website.

Indeed, if this experience takes place in good conditions without problems of downloading the page or visibility of the content, the result will be positive emotions. Otherwise, if it is a bad experience that generates negative emotions, it may even discourage the visitor from returning another time because he will remember certainly the unsuccessful experience.

"When the customer accesses the website, he lives an experience: this experience will automatically be considered as a positive or a negative one. Among the elements that make up this experience, there is color. So it is better to have a positive experience from the beginning than to leave it to chance with a choice of colours that is meaningless..." (1st interviewee: designer and owner of e-commerce website)

Certainly, the lived experience is good enough for the web user to revisit again the previously visited website, but it can also help to revive memories or awaken previously felt feelings.

"Let's say that both emotional and memorization components are so much linked to the lived experience. It may be a good experience that generates positive emotions and encourages the web user to return to the website once again or even to recommend it to others..." (1st interviewee: designer and owner of e-commerce website)

\section{CONCLUSION}

Even though color is a widely studied subject [36], very few studies have focused on the context of e-commerce. 
The literature review focuses on the impact of atmospheric factors in general, such as music, colors, lighting, crowds, etc., on consumers' behavior in the classic point of sale context [28].

Certainly, just like the classic point of sale, there are stimulating elements mentioned by Mehrabian and Russell [14] in the psycho-environmental model; color in this case. On a computer screen, color affects the web user's behavior as well.

Indeed, qualified as an interactive media, the internet plays an important role in the web user's browsing process.

Generally, e-commerce website interfaces aim to place consumers in a particular context by activating the sensory system; hearing and sight mainly, in order to help the web user adopting a positive attitude towards the virtual interface [37] [38].

Our exploratory study sheds light on atmospheric factors in general in the commercial context but is more particularly interested in the importance of the atmospheric component "color" in the context of e-commerce websites and its impact on the Moroccan web user.

Indeed, the interviewed webmasters have judged that a perfect e-commerce website for the Moroccan web user allows a pleasant browsing experience, marked by the ease of access to commercial information that makes you want to discover more topics, products and where the web user feels secure thanks to a payment mechanism that reflects reliability and credibility in his eyes.

Regarding the relevance of atmospheric factors, the structure of the e-commerce website and its design (architecture in terms of colors, graphics and ergonomics) are the factors that interest the web user the most.

Indeed, in a virtual environment, where there is no way to verify, touch or feel the products we want to buy, we try to synthesize all the consumer's feelings in the element "general appearance" of the previewed website. And this is where the importance of color lies.

In the virtual trading environment like in the traditional business environment, visual appearance and appearance in general is the first element of differentiation.

This is why, speaking of the visual appearance dimension, color has certainly an aesthetic role but it also facilitates the attachment and commitment of the web user.

In addition, color allows an immediate recognition of the brand from the first sight of the website. If the user must be captivated by a given element, color is one of the most important elements.

Moreover, web user has to feel that the webmaster has invested a certain amount of time to think about the color or the colors combination of the web site, which contributes in developing the feeling of trust in the web user.

If colors are synchronized and adapted, the web user will be at ease, especially if the used colors rhyme with the idea and purpose of the website and its graphic chart. Adapted and synchronized colors will also, attract the consumer; help him remember the graphic chart and not tire his visual.

However, the feeling of security and trust remains interdependent on the payment method, which must respect world-recognized standards. The impact of design elements in general and color in special, remains secondary compared to the trust felt by the web user.
Besides, evoking the duration of visit, color in a commercial platform can be perceived in different ways.

Warm colors like red are perceived as narrowing the duration of visit. While cold colors are rather seen as extending the visit duration; and this in both classic and virtual places of commerce.

Before concluding, it would be necessary to note some limitations related to our study, particularly the limited size of our sample and the qualitative nature of our research work. However, expanding the sample size and analyzing the issue from a quantitative point of view will give more depth to this study.

\section{REFERENCES}

[1] G. Moss, R. Gunn and J. Heller, Some men like it black, some women like it pink: consumer implications of differences in male and female website design. Journal of Consumer behaviour, 5(4), 328-341, 2006.

[2] T. Lavie and N. Tractinsky, Assessing dimensions of perceived visual aesthetics of web sites. International Journal of humancomputer studies, 60(3), 269-298, 2004.

[3] J.-F. Lemoine, Atmosphère des sites web marchands et réactions des internautes, Revue Française de Marketing, n²17, 2/5, 2008a.

[4] J.-F. Lemoine, L'influence de l'atmosphère des sites web marchands sur les réactions des internautes, 24 ème Congrès International de l'AFM, Paris, 15 et 16 mai, 2008b.

[5] P. Kotler, Atmosphere as a marketing tool, Journal of Retailing, 49, Winter, 48-64, 1973.

[6] L. Dailey, Navigational web atmospherics, explaining the influence of restrictive navigation cues, Journal of Business Research, 57, 7, July, 795-803, 2004.

[7] R. E. Milliman and D. L. Fugate, Atmospherics as an emerging influence in the design of exchange environments. Journal of Marketing Management (10711988), 3, 1993.

[8] A. Mattelart, The Invention of Communication, London/Minneapolis, University Minnesota Press, 1994.

[9] M. Brusatin, Couleurs (Histoire de l'art), in Encyclopaedia Universalis, corpus 6, Paris, 682-688, 1996.

[10] J. Itten, Art de la couleur. Approche subjective et description objective de l'art, édition abrégée, Dessain et Tolra, Larousse, 95, 2004.

[11] J. E. Pelet, The effects of colors of e-commerce websites upon memorization and buying intent, Phd Thesis in Management Sciences (Marketing), Nantes University, France, 2008.

[12] C-F. Shih, Telepresence and bricolage : a conceptual model of consumer experiences in virtual environments, éds. MC Campbell, Machleit KA, Winter, Society for Consumer Psychology Conference Proceedings, 231, 1998.

[13] J.-F. Lemoine, L'atmosphère : un outil de gestion pour les entreprises de services, Direction et Gestion des Entreprises, 32, 168, 28-38, 1997.

[14] A. Mehrabian A. and J. A. Russell, An Approach to Environmental Psychology, Cambridge, MA, MIT Press, 1974.

[15] M. K. Hui and D. K. Tse, What to tell consumer in waits of different lengths : an integrative model of service evaluation, Journal of Marketing, 60, April, 81-90, 1996.

[16] S. Rieunier, L'influence de la musique d'ambiance sur le comportement des consommateurs sur le lieu de vente, Thèse de doctorat en sciences de gestion, Université de Paris-Dauphine (Paris 9), Paris, 2000

[17] L. G. Golden and D.A. Zimmerman, Effective Retailing, Boston, Houghton Mifflin, 1986.

[18] J. A. Bellizzi, A. E. Crowley and R. W. Hasty, The effects of color in store design, Journal of Retailing, 59, 21-45, 1983.

[19] E. R. Spangenberg, A. E. Crowley and P. W. Henderson, Improving the store environment: do olfactory cues affect evaluations and behaviors?. Journal of marketing, 60(2), 67-80, 1996.

[20] C. Derbaix, Le comportement de l'acheteur : voies d'étude pour les années à venir, Recherche et Applications en Marketing, 16, 1, 3-24, 1987.

[21] J. Baker The role of environment in marketing services : the consumer perspective, éds. Czpeil J.A., Congram C., Shanaham J., The Services Marketing Challenge : Integrated for Competitive Advantage, Chicago, American Marketing Association, 79- 84, 1986. 
22] J. Baker, D. Grewal and A. Parasuraman, The influence of the store environment on quality inferences and store image, Journal of the Academy of Marketing Science, 22, 328-339, 1994.

[23] S. J. Greenland and P. J. Mc Goldrick, Atmospherics, attitudes and behavior : modelling the Impact of designed space, The International Review of Retail, Distribution and Consumer Research, 1, 4, 1-16, 1994.

[24] J.-F. Lemoine, Vers une approche globale de 1'atmosphère du point de vente, Revue Française de Marketing, 194, 5-11, 2003.

[25] S. Menon and B. Kahn, Cross-category effects of induced arousal and pleasure on the Internet shopping experience. Journal of retailing, 78(1), 31-40, 2002.

[26] P. Kotler, Marketing during periods of shortage. Journal of Marketing, 38(3), 20-29, 1974.

[27] B. Berman and J. R. Evans, Retail management: A strategic approach (Doctoral dissertation, Univerza v Mariboru, Ekonomskoposlovna fakulteta), 1995.

[28] S. Elbachir, L'impact des facteurs d'ambiance au sein d'un point de vente sur le comportement du consommateur, 2016.

[29] S. A. Ettis, La couleur de l'atmosphère des sites web marchands et le comportement d'approche: rôle médiateur de la stimulation et rôle modérateur des motivations hédonistes. La Revue Gestion et Organisation 8 (2), 75-86, 2016.

[30] A. Mattelart, The invention of communication. U of Minnesota Press, 1996.

[31] L. W. Jacobs and J.F. Suess, Effects of four psychological primary colors on anxiety state, Perceptual and Motor Skills, 41, 1, 207-210, 1975.

[32] N. Kwallek, C. M. Lewis and A. S. Robbin, Effects of Office Interior Color on Workers' Mood and Productivity, Perceptual and Motor Skills, 66, 1, 123-128, 1988.

[33] R. P. Dooley and L. E. Harkins, Functional and attention-getting effects of color on graphic communications. Perceptual and Motor Skills, 31(3), 851-854, 1970.

[34] C. J. Boyatzis and R. Varghese, Children's emotional associations with colors, The Journal of Genetic Psychology, 155, 77-85, 1993.

[35] S. A. Eroglu, K.A. Machleit and L. M. Davis, Atmospheric qualities of online retailing : a conceptual model and implications, Journal of Business Research, special issue on Retail Strategy and Consumer Decision Research, 54, November, 177-184, 2001.

[36] R. Divard and B. Urien, Le consommateur vit dans un monde en couleurs, Recherche et Applications en Marketing, 3-24, 2001.

[37] Q. Chen and W. D. Wells, Attitude toward the site, Journal of Advertising Research, September/October, 27-37, 1999.

[38] L. C. Dailey and E. C. Heath, Bringing Back Your Online Customers : An Exploration of the Role of Atmospherics on the Web, papier de recherche, University of Kentucky, 1999.
Zineb Lahmidi, born in Rabat- Morocco. Holder of :

a bachelor's degree in Economics and Management obtained in 2010 ,

a fundamental degree from the Faculty of Law, Economics and Social

Sciences - Souissi in Rabat - Morocco in 2013, and a master's degree in

Commercial Engineering from the Faculty of Law, Economics and Social Sciences of Salé - Morocco, obtained in 2015.

She is currently a PhD student at the Faculty of Legal, Economic and Social Sciences - Souissi in Rabat, Morocco and a part-time lecturer at both the Faculty of Sciences in Rabat and the Faculty of Legal, Economic and Social Sciences - Souissi in Rabat.

She also participated as a speaker at the International Scientific Conference in Marketing, held on $07^{\text {th }}$ and $08^{\text {th }}$ December 2017at the ENCG- Kénitra under the theme of "The Relationship and Experience between Customer/User/Citizen in the era of Digital, Social Networks and Big Data". She contributed as well contributed as a participant to the 693rd International Conference on E-Education, E-Business, E-Management and E-Learning (IC4E), held on 07 October 2019 in Istanbul, Turkey. 